\title{
Technological Innovations in Managing Challenges of Supply Chain Management
}

\author{
Amita Maxwell*, Sarita Lal \\ Joseph School of Business Studies SHIATS -Deemed University, Allahabad [Uttar Pradesh] 211007, India \\ *Corresponding Author: amita.maxwell@shiats.edu.in
}

Copyright (C 2013 Horizon Research Publishing All rights reserved.

\begin{abstract}
The primary objective of supply chain management is to fulfill customer demands through the most efficient use of resources, including distribution capacity, inventory and labor. In theory, a supply chain seeks to match demand with supply and do so with the minimal inventory. Efficient management of supply chain/value chain remains a challenge for most firms, organizations in order to be competitive need to cut down on the transaction cost related with supply chain and there by increase efficiency or bring about differentiation in product or service line. In the context of an economic slowdown, Business Intelligence solutions become a desirable implementation that can help enterprise top managements get deeper insights into business dynamics and add value to the supply chain in order to synergise business process and gain competitive advantage. Although in a nascent stage for most firms in India the technological breakthrough by way of Radio-frequency identification (RFID) better management of all activities of supply chain is becoming a reality. Technology has immensely brought about sweeping changes in the way businesses function. The present paper aims at understanding supply chain function and the use of RFID technology in reshaping it and the usage of RFID technology in industry with special reference to the retail sector. Future challenges of RFID are also discussed and the way it is able to substitute human function in managing all aspects and thereby reducing inefficiency.
\end{abstract}

Keywords Technological Innovations, RFID Technology, Value Chain, Supply Chain Management, Optimizing Supply Chain

\section{Introduction}

Businesses need to stay competitive to be profitable. In today's hard economical environment, companies have to look very carefully at all aspects of logistics in behest to keep out of the red. Companies need to monitor market conditions, customer preferences, future trends, and demographic shifts and make sound business decisions based on accurate, current, and comprehensive information. This makes business intelligence critical for them.

In today's fast globalising environment, Indian business enterprises have realised the importance of Business Intelligence (BI) solutions as a 'must have' tool that can directly contribute to building long term growth and profitability. CyberMedia Research, the India Business Intelligence / Business Analytics market is slated to grow at a CAGR of $23 \%$ for the period 2010-2014. In a volatile market scenario, it is becoming increasingly important to build greater business efficiencies via real time reporting. As a result the emphasis on information delivery is greater than ever before. In such a scenario BI solutions provide business managers with advanced data analysis. This not only delivers real time business information but also enables them to understand market movements and emerging trends, within and across departments, product lines and geographies.

\section{Objectives of the study}

1.To identify the functioning of RFID with respect to Indian corporate

2.To identify the chief advantages accruing to the business with the usage of RFID

3.To identify the chief limitations and challenges with RFID technology

\section{Research Methodology}

The paper is a secondary data based study and exploratory research of retail sector the study uses literature review approach to make the argument and perspective on RFID with respect to major retail businesses across industry vertical i.e. Wal-Mart, Reliance retail and Future group [owner of brands such as Pantaloon Retail, Big Bazaar and Food Bazaar]. The study is based on secondary data drawn from RFID Journal, market research study [Cyber Media Research], IBEF [India Brand Equity Foundation] study, business articles/news etc.

\section{Supply Chain Management}

A supply chain or logistics network is the system of organizations, people, technology, activities, information and resources involved in moving a product or service from 
supplier to customer. Supply chain activities transform natural resources, raw materials and components into a finished product that is delivered to the end customer. In sophisticated supply chain systems, used products may re-enter the supply chain at any point where residual value is recyclable.

Many of the exchanges encountered in the supply chain will therefore be between different companies who will seek to maximize their revenue within their sphere of interest, but may have little or no knowledge or interest in the remaining players in the supply chain. More recently, the loosely coupled, self-organizing network of businesses that cooperates to provide product and service offerings has been called the Extended Enterprise.

\subsection{Supply Chain Modeling}

The SCOR (Supply Chain Operations Reference) model, developed by the Supply Chain Council, measures total supply chain performance. It is a process reference model for supply-chain management, spanning from the supplier's supplier to the customer's customer. It includes delivery and order fulfillment performance, production flexibility, warranty and returns processing costs, inventory and asset turns, and other factors in evaluating the overall effective performance of a supply chain.

\subsection{Supply Chain Management}

In the 1980s the term Supply Chain Management (SCM) was developed, to express the need to integrate the key business processes, from end user through original suppliers. Original suppliers being those that provide products, services and information that add value for customers and other stakeholders. The basic idea behind the SCM is that companies and corporations involve themselves in a supply chain by exchanging information regarding market fluctuations, production capabilities.

The primary objective of supply chain management is to fulfill customer demands through the most efficient use of resources, including distribution capacity, inventory and labor. In theory, a supply chain seeks to match demand with supply and do so with the minimal inventory. Various aspects of optimizing the supply chain include liason with suppliers to eliminate bottlenecks; sourcing strategically to strike a balance between lowest material cost and transportation, implementing JIT (Just In Time) techniques to optimize manufacturing flow; maintaining the right mix and location of factories and warehouses to serve customer markets, and using location/allocation, vehicle routing analysis, dynamic programming and, of course, traditional logistics optimization to maximize the efficiency of the distribution side.

\section{Radio Frequency Identification (RFID)}

The India market has gradually reached a stage where a need is being felt in more and more sections of industry that use of RFID technologies is necessary. With the present market conditions evolving, adoption of RFID technology will grow and reach a significant level by 2015 according to CyberMedia Research. In today's business climate, the marketplace changes quickly. Businesses must have the tools, technology, and information to enable quick and efficient adaptation to these changes.

Radio-frequency identification (RFID) is the use of a wireless non-contact system that uses radio-frequency electromagnetic fields to transfer data from a tag attached to an object, for the purposes of automatic identification and tracking. Unlike a bar code, the tag does not need to be within line of sight of the reader and may be embedded in the tracked object. Radio Frequency Identification or RFID in short is essentially an enabling technology. The unique advantage of RFID is that it eliminates the requirement of human intervention thus providing immense business value.

RFID can be used in a variety of applications such as:

- Access management

- Tracking of goods

- Tracking of persons and animals

- Toll collection and contact less payment

- Machine readable travel documents

- Tracking sports memorabilia to verify authenticity

- Airport baggage tracking logistics \& Airlines

- Toll passcards and subway passes

- Transportation devices like highway

- Construction companies

\subsection{Operation of RFID}

A radio-frequency identification system uses tags, or labels attached to the objects to be identified. Two-way radio transmitter-receivers called interrogators or readers send a signal to the tag and read its response. The readers generally transmit their observations to a computer system running RFID software or RFID middleware.

The tag's information is stored electronically in a non-volatile memory. The RFID tag includes a small RF transmitter and receiver. An RFID reader transmits an encoded radio signal to interrogate the tag. The tag receives the message and responds with its identification information. This may be only a unique tag serial number, or may be product-related information such as a stock number, lot or batch number, production date, or other specific information.

RFID tags can be either passive, active or battery assisted passive. An active tag has an on-board battery that periodically transmits its ID signal. Tags may either be read-only, having a factory-assigned serial number that is used as a key into a database, or may be read/write, where object-specific data can be written into the tag by the system user. Field programmable tags may be write-once, read-multiple; "blank" tags may be written with an electronic product code by the user. RFID results in saving of a lot of wasteful expenditure and reduces the chances of human error. It is now increasingly used by industry as an effective alternative to the bar code. 
Department of Information Technology has its focus on the R\&D areas of RFID and providing RFID based techno solutions to the Indian industries. With this objective, the ambitious "National RFID Program" project was initiated in April, 2007.

\section{Figure 1}

\begin{tabular}{|c|c|c|c|c|c|c|}
\hline \multicolumn{7}{|c|}{$\begin{array}{l}\text { RFID has a long history that can be traced back to the mid-twentieth } \\
\text { century }\end{array}$} \\
\hline 1940 's & 1950 's & 1960 's & 1970 's & 1980 's & 1990 's & $2000+$ \\
\hline $\begin{array}{l}\text { - Major WW II } \\
\text { development } \\
\text { efforts } \\
\text { - RFID } \\
\text { invented in } \\
1943\end{array}$ & $\begin{array}{l}\text { 'Early } \\
\text { explorations } \\
\text { of RFID } \\
\text { technology } \\
\text { 'Long-range } \\
\text { transponder } \\
\text { systems for } \\
\text { TD of friend } \\
\text { \& foe" (IFF) } \\
\text { for aircraft }\end{array}$ & $\begin{array}{l}\text { - The first } \\
\text { RFID } \\
\text { companies } \\
\text { Sensormatic } \\
\text { \& Checkpoint } \\
\text { are founded } \\
\text { - First } \\
\text { commercial } \\
\text { application } \\
\text { Electronic } \\
\text { Article } \\
\text { Surveillance } \\
\text { (EAS) is } \\
\text { released to } \\
\text { counter theft }\end{array}$ & $\begin{array}{l}\text { - Very early } \\
\text { adopters } \\
\text { implement } \\
\text {-RCA \& } \\
\text { Fairchild } \\
\text { publish } \\
\text { "Electronic } \\
\text { ID System" } \\
\text {-NY \& NJ } \\
\text { Port } \\
\text { Authority } \\
\text { test } \\
\text { electronic } \\
\text { toll } \\
\text { applications }\end{array}$ & $\begin{array}{l}\text { - Commercial } \\
\text { applications } \\
\text { for RFID } \\
\text { enter the } \\
\text { mainstream } \\
\text { - Applications } \\
\text { emerge in } \\
\text { transport. } \\
\text { industrial, } \\
\text { personnel } \\
\text { access and } \\
\text { animal } \\
\text { tagging } \\
\text { - Toli roads } \\
\text { world-wide } \\
\text { are equipped } \\
\text { with RFID }\end{array}$ & $\begin{array}{l}\text { - Emergence of } \\
\text { initial RF } \\
\text { open } \\
\text { standards } \\
\text { - RFID widely } \\
\text { deployed in } \\
\text { toll collection. } \\
\text { animal } \\
\text { tagging and } \\
\text { personal } \\
\text { identification } \\
\text { - MIrT founds } \\
\text { the Auto-lD } \\
\text { Center }\end{array}$ & $\begin{array}{l}\text { - First CPG I } \\
\text { Retailer auto- } \\
\text { ID pilots } \\
\text { launched } \\
\text { - Gillette buys } \\
500 \text { million } \\
\text { tags from } \\
\text { Alien Tech. } \\
\text { - Wal-Mart. } \\
\text { Tesco \& the } \\
\text { US } \\
\text { Department } \\
\text { of Defense } \\
\text { announce } \\
\text { supplier } \\
\text { mandates }\end{array}$ \\
\hline
\end{tabular}

\section{Use of RFID in Industries}

On the lines of global retail biggies like Wal-Mart, Carrefour and Tesco, which use radio frequency identification (RFID), companies like Future Group and Reliance Retail are in the early stages of RFID adoption.

RFID in India is driven by RFIDAI - RFID Association of India - a not for profit organization promoting the technology. The association has not been able to make a remarkable push so far for many reasons, mostly market driven. But, it is committed towards making the industry achieve respectable size in India.

Reliance Retail, one of India's largest and only private Fortune 500 company has been testing RFID technology and is preparing applications for use at a large number of its hypermarkets and supermarkets. The company has already equipped these stores with data ports and wireless computer networks able to support RFID systems.

Reliance Retail has always been focused on improving business process, it considers RFID an ideal tool for:

- ensuring adherence to retail processes and monitoring activities in stores

- committed to driving process compliance to maintain low productivity levels

- drive process compliance on a near real-time basis a key performance indicator (KPI)

- to support its operations tracking of reusable crates of fresh food; item- and case-level tracking of high-value goods and pallet and case tagging of various goods

- Improve read rates(The process of retrieving data stored on an RFID tag by sending radio waves to the tag and converting the waves the tag sends back into data) and reduce shipping and receiving errors while increasing productivity

The retail arm of Future Group, Pantaloon Retail Indian Limited (PRIL) operates its stores through hypermarkets and supermarkets. PRIL's hypermarket store Big Bazaar was a combination of a supermarket and a department store. The Unique Selling Proposition of the Big Bazaar store was low prices and the best price proposition being offered to customers. The stores were designed in such a way that it gave the consumers a feel of an Indian bazaar (market). Future Group's shift to RFID technology in 2004 is strategic. The move makes a lot of business sense for a huge retail venture like Future Group and will offer competitive advantage. Future Group can accrue various benefits from RFID technology implementation. RFID increases efficiency levels as it offers complete visibility in the supply chain and will be very effective in decision making or dealing with goods that age or perish.

In January 2005, Wal-Mart required its top 100 suppliers to apply RFID labels to all shipments. To meet this requirement, vendors use RFID printer/encoders to label cases and pallets. These smart labels are produced by embedding RFID inlays inside the label material, and then printing bar code and other visible information on the surface of the label.

Swire Coca-Cola HK employs the technology to track cylinders and tanks within its facilities and at customer sites. Swire Coca-Cola HK, a soft-drink manufacturer located in Hong Kong, faced several daunting inventory-management challenges. Each day, the company delivers approximately 10,000 carbon dioxide cylinders and soft-drink post-mix (PM) tanks - which contain syrup to be mixed to create beverages - to roughly 3,000 customers, including major dining chains McDonald's, Fairwood 
and Maxim's Group. The company found it difficult to track all the cylinders and tanks as they circulated throughout the city. The process of tracking container deliveries to customers, as well as returns to Swire's warehouse, was performed manually, with operators recording the containers' status on paper documents. This often led to inaccurate status reports due to human error, and did not provide the company with real-time visibility into its inventory's whereabouts. Swire estimates it lost 500 tanks and cylinders annually.

Copacafe deployed a passive RFID warehouse-management solution to improve efficiencies and lower costs. Brazil's Copacafé, a cooperative founded in 1978, provides assistance to 1 percent of the nation's coffee growers, including storing, blending and selling the beans. That involves receiving the beans at Copacafé's warehouse, as well as identifying their origins and classifying their grade. But the Minas Gerais-based cooperative had difficulty locating batches of coffee beans stored in bags within its warehouse, so it adopted a radio frequency identification solution to streamline these processes. Once coffee is received at Copacafé, a sample of the beans is tested and classified; the same farm can produce different coffee crops annually. Before RFID was adopted, the bags were identified via handwritten labels that included the test results and information regarding each bag's contents, and its location within the warehouse was stored on a spreadsheet. But inevitably, the bags would end up being moved as forklift drivers searched for those they needed to pick up in order to fulfill orders.

Wal-Mart Stores Inc. and a number of its suppliers are using Dallas distribution center as the starting point for a technology that's targeted to one day replace the bar code. The radio frequency information, or RFID, tags provide automatic tracking of pallets and cases of goods. The RFID tags contain a chip that is imparted with information. In a backshop retail environment, the tags will contain the details of what is in a case or on a pallet of goods. Rather than have a worker with a handheld scanner logging in barcodes, the system will let a computer system use a radio signal to log the goods as they arrive at the loading dock. The tags can also be used in the manufacturing process, can help suppliers become more efficient, and the tags will help companies on both ends know where their products are at all times.

A major U.S. automotive battery supplier has added radio frequency identification technology to storage racks, making it possible for the company to view the locations of its products and replenish stock at the appropriate times, thereby enabling it to provide improved services to its distributors, dealers and retailers. The battery company provides its products to auto parts stores, repair shops and other merchant locations. It sends drivers to replenish products as they are sold, as well as installing an RFID reader module and antennas in storage or display racks at dealership sites, would provide greater visibility into when products were being sold at each location. The system can also track each battery's manufacturing date, which helps the company to rotate new batteries as necessary, in order to clean and refresh them in the event that they have remained on the shelf for a specified length of time.

Finally, when as the batteries reach the end of their lifespan, they need to be returned to the manufacturer, which disposes of the hazardous materials and recycles other materials properly. Using a reader at that point, the company will be able to have details regarding the number of batteries being recycled, as well as historic data about the performance (length of life) of specific battery models.

\section{How RFID Can Help Optimise Supply Chain Management}

Squeezing cost and inefficiency out of the supply chain has been one of the recurring mantras of the industrialised world for the past 50 years. The concept, as we would recognise it, has its roots in the Toyota Production System (TPS) of the 1950s and has been refined and improved significantly over the years to the point where one might expect that the most sophisticated devotees today have optimised their supply chains. The journey towards perfection, however, never ends. In the very near future, the adoption of sensor-based Radio Frequency Identification (RFID) technology will allow the creation of the real-time, sensor-connected manufacturing plant. By adding RFID tags to every product, tool, resource and item of materials handling equipment, manufacturers will be able to get better demand signals from customers and the market.

At its core, RFID is simply an enabling technology that has the potential of helping retailers provide the right product at the right place at the right time, thus maximising sales and profits. RFID provides the technology to identify uniquely each container, pallet, case and item being manufactured, shipped and sold, thus providing the building blocks for increased visibility throughout the supply chain.

The technology will bring benefits to a wide range of industries, as we shall see, but one of the main drivers of RFID adoption has been the retail sector, led by Wal-Mart in the US. It is estimated that US retail giant Wal-Mart alone could save $\$ 8.35$ billion annually with RFID - that's more than the total revenue of half the companies in the Fortune 500 .

This massive total is made up as follows: $\$ 600$ million through avoiding stock-outs; $\$ 575$ million by avoiding theft, error and vendor fraud; $\$ 300$ million through better tracking of a billion pallets and cases; $\$ 180$ million through reduced inventory; and a huge $\$ 6.7$ billion by eliminating the need to have people scan barcodes in the supply chain and in-store. Small wonder, then, that Wal-Mart is investing $\$ 3$ billion in RFID over several years and is one of the leading proponents of RFID implementation.

RFID promises to revolutionise supply chains and usher in a new era of cost savings, efficiency and business intelligence. The potential applications are vast as it is relevant to any organisation engaged in the production, movement or sale of physical goods. This includes retailers, distributors, logistics 
service providers, manufacturers and their entire supplier base, hospitals and pharmaceuticals companies, and the entire food chain.

It has the potential to improve efficiency and visibility, cut costs, delivers better asset utilisation, produce higher quality goods, reduce shrinkage and counterfeiting, and increase sales by reducing out-of-stocks. It can even help improve the safety of the food and pharmaceuticals we buy. The key to delivering all these benefits is cost. The falling price of RFID tags is a driver for the technology.

Tag pricing is critical. Industry is hoping that tag manufacturers can hit 5 cents per unit, and that is being regarded as a breakthrough level. Yet even that is still too expensive for, say, an individual can of Coke, which is why packaging companies and other researchers are looking at innovative ways to apply this technology. In the coming years, at least, we are likely to see RFID tags and barcodes existing side by side.

But early adopters of the technology are by no means confined to the retail sector. Among the Oracle customers undertaking trials or actively implementing RFID today are DHL in the Americas and Europe, NASA in the USA, YCH in Singapore, Dolomiti Superski in Italy, McCarran Airport in Las Vegas and NHK in Japan.The business value of RFID is undeniable. It will create winners all round. Manufacturers will benefit from increased inventory visibility, more efficient use of labour, better line operations and improved fulfilment. Retailers can benefit from reduced inventory, because the improved supply chain visibility allows better demand forecasting, lower safety stocks and lower order cycle times. Automated data capture will also cut costs by reducing labour in the store and warehouse, and fewer sales will be lost through out-of-stocks.

And it's not just the retail sector that will benefit. Manufacturing industry as a whole will be able to fine-tune the supply chain to optimise efficiency and minimise inventory and waste.

RFID is best viewed as part of a broader spectrum of sensor-based technologies. This includes the now-familiar technologies of barcode and magnetic stripe, as well as integration with equipment such as scales and dimensioning devices and sensors for such things as temperature, position and moisture. Hybrid sensors that combine RFID tags with temperature sensors, all embedded in a barcode label, are already available.

As a result, any RFID capability must be part of a comprehensive technology and applications infrastructure that can collect events from these disparate sources, combine the data into composite transactions and then automatically trigger the appropriate business process.

Two things are crystal clear: RFID is here to stay, and enterprises can achieve significant business value from embracing it. Due to the high cost of investing in RFID, each company needs to evaluate its own business processes to determine where and if RFID can be applied to improve operational and process efficiencies to positively affect the bottom line.

If that evaluation suggests that the technology can benefit the business, the next step is to develop a roadmap for RFID implementation.

\section{RFID Reshapes Supply Chain Management}

RFID will be a major advance in supply chain management, but enterprises will need to do considerable upfront planning and testing to successfully implement and integrate the technology. Although radio-frequency identification technology can be used in a broad range of applications, ITs focus right now should be on the supply chain. RFID will have a significant impact on every facet of supply chain management-from the mundane, such as moving goods through loading docks, to the complex, such as managing terabytes of data as information about goods on hand is collected in real time.

RFID will initially be used to manage the identification of large lots of goods - for example, at the pallet and carton levels. RFID tags, therefore, must have unique serial identifier information that associates each lot with a corresponding bill of lading sent from the originator. Because RFID readers can scan tags many times during a 1-second period, the serial identifier will prevent the application making the data request from getting multiple counts of the same items.

RFID tags are classified as passive or active. Passive tags work by taking the energy received from the reader through a tags antenna and using that energy to transmit stored data back to the reader. Passive tags will likely be more widely used, at least at first, because of their low cost.

Active tags include their own power supply, usually a battery, to transmit information directly to a reader. The battery can also be used to help power or interact with other devices. For example, a company shipping perishable goods may want to use active tags that integrate with thermometers to ensure the goods are kept at an acceptable temperature.

RFID tags also have the potential, at the individual-item level, to store information that can be relevant to broader applications. For example, individual items with embedded RFID tags could contain information about warrantee and prior service to make it easier for companies to service those items.

\section{Specific Proposals for implementing RFID Technology for Indian market}

As the RFID technology is in its nascent stage and the Indian retail market is experimenting with it in order to explore the prospects, the Indian retail sector should use RFID technology primarily to economize and optimize its supply chain. Supply chain/value chain is a chain of activities that a firm operating in a specific industry 
performs in order to deliver a valuable product or service for the market. The concept comes from business management and was first described and popularized by Michael Porter in 1985 in his book, Competitive Advantage: Creating and Sustaining Superior Performance. The value chain categorizes the generic value-adding activities of an organization or the primary activities which includes; inbound logistics, operations, outbound logistics, marketing \& sales and service. Managing these core activities for creating strategic/distinctive competence for superior performance in comparison to competitors is inevitable in today's time. RFID can be implemented for the following operations:

1. The focus of Indian retail sector should be on firstly Tactical SCM (Supply Chain Management) which involves shorter planning cycle. It is concerned with demand planning, inventory and supply planning. Secondly Operational SCM which involves current planning activities measured in weeks it involves majority of operations. It is concerned with demand fulfillment, scheduling, production, location, inventory, and transportation and monitoring. Strategic SCM at executive level may take several years hence Indian markets can see it as an incremental improvement in supply chain identification technology.

2. Procurement and Distribution: As RFID can be used to label different products, shelves \& bins in the center. The quantity of the product required from the center can be entered in the computer, which can update the information on the main central server/merchandise management system. This will enable the packaging department to get accurate information such as storage, packaging \& shipping, thus saving time and will enable supervisors to monitor their employees closely in order to guide them and give directions. This will help in satisfying customer needs quickly \& improve level of efficiency of distribution center management operations. This follows directly from the expectation that RFID will improve supply chain efficiency for retail firms, resulting in lower costs.

3. Logistics Management: This involves fast \& responsive transportation system. Vehicles/transport system servicing the distribution centers to replenish the store shelves can be monitored. RFID technology connects all phases of the supply chain, from resourcing and manufacturing to inventory and distribution therefore it can be utilized as a popular track-and-trace solution in India. RFID creates real time information links that can be used to speed production, improve quality and streamline delivery. Identification of shipping units can significantly improve the efficiency of process chain.

4. Inventory Management: By making use of RFID technologies, different processes like efficient picking, receiving \& proper inventory control of the products along with easy packing and counting of the inventories can be ensured. Keeping track of the inventory in stores, deliveries and backup merchandise in stock at the distribution centers can be done. Updating Inventory system immediately will result in reduction in out of stock inventory cost. As much of these tasks are challenging for humans to track assets and inventory and also labour intensive. RFID usage can economize the operations.

\section{Comprehensive Analysis of the Experience of the EU and U.S. Markets}

Based on the study conducted -Gordon Bitko, Dissertation (2007), on "RFID in the Retail Sector A Methodology for Analysis of Policy Proposals and Their Implications for Privacy, Economic Efficiency and Security" by Pardee RAND Graduate School (PRGS) dissertation series, RAND Corporation, it can be analyzed that RFID is an enabling technology balancing the benefits are the large costs associated with developing and deploying appropriate RFID technology and integrating the RFID technology with other technologies, and complying with any government policy mandates.

Costs and benefits of RFID technology for large retail firms and their suppliers in U.S. and European market are based on the premise that information is static and often not up-to-date, systems are poor at dealing with dynamic demand. Analysis shows the scope of many of the problems arising from inadequacies in the supply chain is substantial. Retailer out of stocks are estimated to cost as much as $6 \%$ of sales, and over $50 \%$ of delivery trucks are empty or are returning unwanted or expired product. (RFID in the Supply Chain: A Balanced View, Noonan, Cheyne et al. 2004). Retail firms have identified a whole host of prospective opportunities to address these challenges using RFID. The majority relate to:

Improved logistic efficiency across the supply chain, from raw materials supply all the way up to the retail Point-Of-Sale (POS), and customer satisfaction even beyond the POS. Some of these benefits are specific to particular members of the supply chain, while others occur between elements of the chain, or across its entire breadth.

Real-time inventory control and shrinkage in labor cost by reducing the amount of manual intervention required during the distribution process is becoming a reality, it has resulted in quick respond to missing inventory, and improved retail stocking by better management of store-shelf inventory. (RFID: The Right Frequency for Government. Washington DC, IBM Center for the Business of Government, Wyld 2005).

Retailers benefits include improved POS checkout through the elimination of the need to handle each product requiring a bar code scan, better sales support by automation of returned goods, and improved management of floor inventory. (Moving Forward with Item-Level Radio Frequency Identification in Apparel/Footwear,Kurt Salmon Associates.,Kurt Salmon Associates 2005).

Wal-Mart has been the major driving force behind the recent explosion in RFID adoption, many companies have adopted Wal-Mart's perspective on the technology. Improving 
supply chain efficiency of retailers and other "logistics intensive" organizations may only be a short-term impact of RFID. Many experts believe that in the future RFID may have a more profound impact on business across the globe, better supply chain visibility achieved with RFID can help companies to cut down costs associated with lost supplies [Asif and M. Mandviwalla, Integrating the supply chain with RFID: A technical and business analysis, Communications of the AIS, vol. 15, no. 24, March 2005, pp. 393-426].

Although there is a growing realization of the potential of RFID, there is no guarantee that RFID will actually leave the supply chain identification domain. The long-term impact of RFID may go beyond improving supply chain efficiency in U.S retail sector. An analogy to the Internet can be drawn here [Krotov.V and Junglas. I, "RFID as a Disruptive Innovation" Journal of Theoretical and Applied Electronic Commerce Research ISSN 0718-1876 Electronic Version VOL 3 / ISSUE $2 /$ AUGUST 2008 / 44-59]. In the long-term, RFID may have the potential to take the concept of the information superhighway to a level previously unimaginable.

In the final analysis it can be drawn that evidence of RFID having the Potential to Become a Disruptive Innovation exists in today's business realm. With this perspective in mind, it is important to determine the likely path of RFID evolvement as well as its potential long-term impact. It is possible that RFID, just like the Internet, will take the path of a disruptive innovation. According to [C.M. Christensen, A.D. Anthony and E.A. Roth, Seeing What's Next, Harvard Business School Press: Boston, Massachusetts, 2004]:

Disruptive innovations introduce a new value proposition. They either create new markets or reshape existing markets (p.xvii)

Indeed, several companies have already used RFID to create new value propositions:

- Cafes and stores in Seattle (U.S.) are using RFID technology for marketing products and services $[J$. Bostrom (2005, May) Marketing via RFID comes to Seattle, Computerworld-Online]. At the core of this new advertisement system are the so-called "activation fields" (areas covered by the field of an RFID reader) and active RFID tags that are carried by customers of this system.

In the final analysis a forward-looking perspective on RFID technology can be drawn having a revolutionary impact on the business model of present retail scenario across the globe and moving beyond sustaining core value chain activities of retail giants like Kimberly Clark, Wal-Mart, Gillette, Carrefour, Schwarz, Aldi, Tesco, Metro, and Kraft Foods etc., in the U.S and EU markets.

\section{Future Challenges for RFID}

1.As per CyberMedia Research, the main issues that the RFID faces in India are limited knowledge about RFID applications among decision makers. RFID is seen as add-on cost, lack of government regulations and standardization.
Cost is still an issue. Potential business users want to see RFID tag costs affordable to the larger end-user community.

2. Availability of labour at cheap rates and in large numbers to do mundane and routine jobs of manning, guarding, cleaning, refilling, serving etc. discourages increase in utilization rates of technology solutions.

3 .EPC global Inc., the standards body that manages UPC (universal product code) information in bar codes, sets the standards for how basic product information is encoded in the RFID chips. (RFID chips are designed to augment bar codes.) EPCglobal will establish the standards on how information is passed from RFID readers to various applications, as well as from application to application, in the supply chain.

4. A primary RFID security concern is the illicit tracking of RFID tags. Tags, which are world-readable, pose a risk to both personal location privacy and corporate/military security. Such concerns have been raised with respect to the United States Department of Defense's recent adoption of RFID tags for supply chain management. More generally, privacy organizations have expressed concerns in the context of ongoing efforts to embed electronic product code (EPC) RFID tags in consumer products.

5. The path to RFID is not without its obstacles: tag costs are still high; readers can't always read all the cases on a pallet; one frequency and one tag design does not fit all; standards are in a state of flux; end-users lack real RFID knowledge; and radio interference can upset the best-laid plans. Wal-Mart laid down its marker as an RFID pioneer by issuing mandates to its suppliers throughout the entire supply chain.

\section{Conclusion}

India is a huge market by geography apart from the population, managing distribution and logistics for such a wide and diverse network has always been a tall order. RFID can become a key enabler. The Manufacturing sector is growing and increasing its contribution to India's GDP. In the initial years of the 11th Five-Year Plan, the growth rate of manufacturing sector stood at $10.3 \%$ compared to $9.3 \%$ in the 10th Five-Year Plan. Similarly, Agriculture grew at 3.2\% compared to $2 \%$ for the same period. As per the National Manufacturing Policy 2011, the Government of India would like to see manufacturing sector jobs increase by 100 million by 2020 .

In October 2005 the University of Arkansas' Information Technology Research Institute released a report on its preliminary study of the impact of RFID on reducing retail out-of-stocks and concluded that RFID reduced out of stocks by $21 \%$ over non-RFID based stores. RFID tags, a technology once limited to tracking cattle, are tracking consumer products worldwide. Many manufacturers use the tags to track the location of each product they make from the time it's made until it's pulled off the shelf and tossed in a shopping cart.

Soon, they may even track preference for chunky or 
creamy peanut butter. Some critics say RFID technology is becoming too much a part of our lives -- that is, if we're even aware of all the parts of our lives that it affects. RFID tags won't entirely replace bar codes in the near future -- far too many retail outlets currently use UPC scanners in billions of transactions every year. But as time goes on we'll definitely see more products tagged with RFIDs and an increased focus on seamless wireless transactions.

There is no doubt that RFID and other sensor-based technologies present massive potential for creating competitive advantage. Companies in these and other industries will find that incorporating these technologies into their information infrastructure and integrating them into their business processes will provide substantial business benefit. But, to realise maximum return on investment, they need to leverage their information architecture strategically. If RFID is to create value for business, first it will create data - masses of data. Users will need to ensure they have an IT architecture that can appropriately manage, analyse and respond to this new wealth of data being captured to truly gain visibility into their supply chain

\section{REFRENCES}

[1] Martein Meints (2007), D3.7 A Structured Collection on Information and Literature on Technological and Usability Aspects of Radio Frequency Identification (RFID), FIDIS deliverable 3(7), June 2007.

[2] Paolo Magrassi (2001). "A World Of Smart Objects: The Role Of Auto Identification Technologies http://www.gartner.com. Retrieved 2007-06-24.

[3] Pete Harrison (2009-07-28). "EU considers overhauling rules for lost air luggage". Reuters. http://www.reuters.com/article/ rbssIndustryMaterialsUtilitiesNews/idUSLS63631320090728. Retrieved 2009-09-09.

[4] Sen, Dipankar; Sen, Prosenjit; Das, Anand M. (2009), RFID For Energy and Utility Industries, PennWell, ISBN 978-1-59370-105-5, pp. 1-48

[5] Daniel M. Dobkin, The RF in RFID: Passive UHF RFID In
Practice, Newnes 2008 ISBN 978-0-7506-8209-1, chapter 8

[6] John R. Vacca Computer and information security handbook, Morgan Kaufmann, 2009 ISBN 0-12-374354-0, page 208

[7] Bill Glover, Himanshu Bhatt ,RFID essentials , O'Reilly Media, Inc., 2006 ISBN 0-596-00944-5, pages 88-89

[8] Hacking Exposed Linux: Linux Security Secrets \& Solutions (third ed.). McGraw-Hill Osborne Media. 2008. p. 298. ISBN 978-0-07-226257-5.

http://books.google.com/?id=f5Vz08spzw8C\&printsec=front cover.

[9] Genesis of the Versatile RFID Tag, RFID Journal

[10] Landt, Jerry (2001). "Shrouds of Time: The history of RFID" (PDF).AIM,Inc..http://www.transcore.com/pdf/AIM\%20shro uds_of_time.pdf. Retrieved 2006-05-31.

[11] Miles, Stephen Bell (2011). RFID Technology and Applications. London: Cambridge University Press. pp. 6-8.

[12] Gordon Bitko, Dissertation (2007), RFID in the Retail Sector A Methodology for Analysis of Policy Proposals and Their Implications for Privacy, Economic Efficiency and Security. RAND Corporation, http://www.rand.org/

[13] Noonan, G., M. Cheyne, et al. (2004). RFID in the Supply Chain: A Balanced View, AMCOR Australasia; Hewlett-Packard.

[14] Wyld, D. C. (2005). RFID: The Right Frequency for Government. Washington DC, IBM Center for the Business of Government.

[15] Kurt Salmon Associates (2005). Moving Forward with Item-Level Radio Frequency Identification in Apparel/Footwear, Kurt Salmon Associates.

[16] Krotov.V and Junglas. I, "RFID as a Disruptive Innovation" Journal of Theoretical and Applied Electronic Commerce Research ISSN 0718-1876 Electronic Versión VOL 3 / ISSUE 2 / AUGUST 2008 / 44-59.

[17] C.M. Christensen, A.D. Anthony and E.A. Roth, Seeing What's Next, Harvard Business School Press: Boston, Massachusetts, 2004.

[18] J. Bostrom (2005, May) Marketing via RFID comes to Seattle, Computerworld [Online]. Available: http://computerworld.com/mobiletopics/mobile/technoloqv/st orv/0,10801,101951,00. html. 